\title{
PELAKSANAAN EVALUASI UNTUK MENGUKUR PENCAPAIAN DALAM PEMBERIAN ASUHAN KEPERAWATAN
}

\author{
ANGEL OKTAVIA PURBA / 181101099 \\ angeloktavia013@gmail.com
}

\begin{abstract}
ABSTRAK
Evaluasi adalah penilaian dengan cara membandingkan perubahan keadaan pasien ( hasil yang diamati) dengan tujuan dan kriteria hasil yang dibuat dalam tahap perencanaan. Tujuan dari penulisan ini adalah untuk mengetahui apa itu evaluasi, apakah tujuan dilakukannya evaluasi dalam keprawatan dan untuk mengetahui bagaimana tahapan dalam evaluasi keperawatan ini. Metode penulisan ini adalah Literature Riview, dimana ini menganalisis artikel yang relevan dan berfokus pada tema tahap evaluasi keperawatan. Hasil Berdasarkan pencarian literature didapatkan apa defenisi evaluasi keperawatan, apa tujuan dilakukannya tahap evaaluasi keperawatan dan bagaimana dan apa saja tahapan dalam evaluasi keperawatan.
\end{abstract}

Kata kunci : Proses keperawatan, Evaluasi keperawatan, Asuhan keperawatan.

\section{LATAR BELAKANG}

Pencapaian kualitas asuhan keparawatan dirumah sakit saat ini belum ada standar yang baku.Tuntutan masyarakat dalam pelayanan kesehatan beraneka ragam, untuk menjawab hal tersebut pen-ting adanya pelayanan keperawatan yang terinte-grasi. Pelayanan keperawatan merupakan bagian dari pelayanan kesehatan rumah sakit yang akan mendukung proses penyembuhan dan pemulihan kesehatan pasien yang dirawat, serta mutu pelayanan keperawatan akan mencerminkan mutu pelayanan pada pasien. Maka untuk melihat pencapaian asuhan keperawatan yang telah diberikan maka perawat harus melakukan evaluasi terhadap asuhan yang diberikan. Evaluasi merupakan tahap yang harus dilakukan setelah tahap perencanaan yang merupakan perbandingan dengan sistematis dan terencana antara hasil akhir yang teramati dan tujuan atau hasil kriteria yang dibuat pada tahap perencanaan. Evaluasi dilakukan secara berkesinambungan dengan melibatkan klien dan tanaga kesehatan lainnya. 


\section{TUJUAN}

Tujuan dari penulisan ini adalah untuk mengetahui apa itu evaluasi, apakah tujuan dilakukannya evaluasi dalam keprawatan dan untuk mengetahui bagaimana tahapan dalam evaluasi keperawatan ini.

\section{METODE}

Metode penulisan ini adalah Literature Riview, dimana ini menganalisis artikel yang relevan dan berfokus pada tema tahap evaluasi keperawatan. Adapun sumber yang digunakan dalam literature ini menggunakan sumber dari buku teks, jurnal dengan memasukan kata kunci evaluasi dalam proses keperawatan. Adapun jurnal yang saya yang digunakan merupakan jurnal yang diiterbitkan pada 10 tahun terakhir.

\section{HASIL}

Berdasarkan pencarian literature didapatkan apa defenisi evaluasi keperawatan, apa tujuan dilakukannya tahap evaaluasi keperawatan dan bagaimana dan apa saja tahapan dalam evaluasi keperawatan.

\section{PEMBAHASAN}

Evaluasi adalah penilaian dengan cara membandingkan perubahan keadaan pasien ( hasil yang diamati) dengan tujuan dan kriteria hasil yang dibuat dalam tahap perencanaan. Evaluasi merupakan tahap yang harus dilakukan setelah tahap perencanaan yang merupakan perbandingan dengan sistematis dan terencana antara hasil akhir yang teramati dan tujuan atau hasil kriteria yang dibuat pada tahap perencanaan. Evaluasi dilakukan secara berkesinambungan dengan melibatkan klien dan tanaga kesehatan lainnya. Adapun tujuan dari evaluasi yaitu untuk 1.memodifikasi rencana tindakan keperawatan, 2.meneruskan rencana tindakan keperawatan. 3. Menentuka apakah tujuan keperawatan terlah tercapai atau belum. 4. Melihat dan manila kemampuan klien dalam mencapai tujuan. 5. Mengkaji penyebab jika tujuan asuhan keperawatan belum tercapai.

Tahapan proses evaluasi keperawatan antaralain

1. Mengukur pencapaian tujuan.

A .Tujuan aspek kognitif, pengukuran perubhan kognitif dapat dilaksanakan 
dengan cara 1) Interviu/Tanya jawab, dilakukan untuk menanyakan kembali segala sesuatu yang telah dijelaskan oleh perawat untuk mengklarifikasi pemahaman klien/ keluarga terhadap pengetaahuan yang telah diberikan. 2) Komprehensif, pertanyaan komprehensif adalah pertanyaan yang diajukan berdasarkan pemahaman klien terhadap perubahan yang terjadi pada tubuhnya.

3) Aplikasi fakta, Pertanyaan berdasarkan aplikasi data adalah pertanyaaan yang ditujukan untuk mengidentifikasi pemahaaman klien pada tingkat aplikasi

4) Tertulis. Teknik yang digunakan untuk mengkur pencapaian tujuan pencapaian tujuan kognitif adalah dengan mengajukan pertanyaan tertulis.

B. Tujuan aspek sfektif, pengukuran pencapain tujuan aspek apektif dapat dilakukan dengan dua cara yaitu : Observasi yaitu untuk melakukan pengamatan secara langsung terhadap perubahan emosi klien dan feed back dari kesehatan lain juga dapat dipakai sebagai salah satu informasi tentang aspek afektif klien.

C. Psikomotor, pengukuran psikomotor dapat dilakukan melalui observasi secara langsung terhadap perubahan perilaku klien.

D. Perubahan fungsi tubuh, Perubahan fungsi tubuh merupakan komponen yang paling sering menjadi kriteria evaluasi. Untuk mengukur perubahnnya dapat dilakukan dengan tiga cara yaitu observasi, interviu, dan pemeriksaan fisik.

Evaluasi terbagi atas dua jenis yaitu, evaluasi formatif dan evaluasi sumatif. Evaluasi formatif berfokus pada aktivitas proses keperawatan dan hasil tindakan keperawatan. Evaluasi formtif ini dilakukan segera setelah perawat mengimplementasikan rencana yang tela dilaksanakan. Kemudian evaluasi sumatif yaitu evaluasi yang dilakukan setelah semua aktivitas proses keperawatan selesai dilakukan. Evaluasi sumatif ini bertujuan untuk menilai ffan memonitori kualitas asuhan keperawatn yang telah diberikan.

Evaluasi pada dasarnya dilakukan untuk mengetahui apakah tujuan yang ditetapkan sudah dicapai atau belum. Oleh karena itu, evaluasi dilakukan sesuai dengan kerangka waktu penetapan tujuan (evaluasi hasil), tetapi selama proses pencapaian terjadi 
pada klien juga harus selalu dipantau ( evaluasi proses).

Untuk memudahkan perawat dalam mengevaluasi atau memantau perkembangan klien, digunakan komponen SOAP/SOAPIE/SOAPIER. Pengertian SOAPIER yaitu :

$\mathbf{S}$ artinya data subjektif. Perawat dapat menuliskan keluhan pasien yang masih dirasakan setelah dilakukan tindakan keperawatan.

O artinya data objektif. Data objektif yeitu data berdasarkan hasil pengukuran atau hasil observasi perawat secara langsung pada klien dan yang dirasakan klien setelah dilakukan tindakan keperawatan.

A artinya analisis. Interpensi dari data subjektif dan data objektif. Analisis merupakan suatu masalah atau diagnosis keperawatan yang masih terjadi atau juga dpat dituliskan masalah diagnostic baru yang terjadi akibat perubahan status kesehatan klien yang telah terdentifikasi datanta dalam data subjektif dan objektif. P artinya planning. Perencanaan keperawatan yang akan dilanjutkan, dihentikan, dimodifikasi atau perencanaan yang ditambahkan dari rencana tindakan keperawatan yang telah ditentuka sebelumnya. I artinya implementasi. Implementasi adalah tindakan keperawatan yang dilakuakn sesuatu dengan instruksi yang telah teridentifikasi dalam komponen $\mathrm{P}$ (perencanaan).

E artinya evaluasi. Evaluasi adalah respond klien setelah dilakukan tindakan keperawatan. $\mathbf{R}$ artinya reassessment. Reassessment adalah pengkajian ulang yang dilaukan terhadap perencanaan setelah diketahui hasil evaluasi.

\section{KESIMPULAN}

Evaluasi adalah penilaian dengan cara memabandingkan perubahan keadaan pasien ( hasil yang diamati) dengan tujuan dan kriteria hasil yang dibuat dalam tahap perencanaan. Adapun tujuan dari evaluasi yaitu untuk 1.memodifikasi rencana tindakan keperawatan, 2. meneruskan rencana tindakan keperawatan. 3. Menentuka apakah tujuan keperawatan telah tercapai atau belum. 4. Melihat dan manila kemampuan klien dalam mencapai tujuan. 5. Mengkaji penyebab jika tujuan asuhan keperawatan belum tercapai. Untuk memudahkan perawat dalam mengevaluasi atau memantau perkembangan klien, digunakan 
komponen SOAP/SOAPIE/SOAPIER. Pengertian SOAPIER.

\section{SARAN}

Tahap evaluasi merupakan tahap yang dilakukan setelah tahap perencanaan, tahap evaluasi sangat penting dilakukan untuk menilai apakah tujuan tindakan keperawatan yang kita berikan berhasil atau tidak dan untuk mengukur apakah tujuan tindakan keperawatan yang diberikan tercapai atau tidak. Untuk itu perawat perlu memahami lebih dalam melaksanakan tahap evaluasi, agar dapat mengukur seberapa berhasilnya tujuan yang diberikan.

\section{DAFTAR PUSTAKA}

Allen, C. V. (1998). Memahami Proses Keperawatan. Jakarta. EGC.

Asmadi. (2008). Konsep Dasar Keperawatan. Jakarta. EGC.

Budiono \& Sumirah,B,P.(2016). Konsep Dasar Keperawatan (Ed 2). Jakarta. Bumi Medika.

Dermawan, Deden. (2012). Proses Keperawatan : Penerapan Konsep Dan Kerangka Kerja. Yogyakarta : Gosyen Publishing.
Deswani. (2009). Proses Keperawatan dan Berpikir Kritis. Jakarta : Salemba Medika.

Doengens, M. E., Mary, F. M \& Alice, C. G. (1999). Rencana Asuhan Keperawatan ed 3. Jakarta. EGC.

Haryanto. (2007). Konsep Dasar Keperawatan Dengan Peemetaan Konsep. Jakarta : Salemba Medika.

Hidayat, A. Aziz Alimut. (2004). Pengantar Konsep Dasar Kepperawatan. Jakarta. Salemba Medika.

Lismidar,H.(1990).Proses

Keperawatan. Jakarta : Universitas Indonesi.

Potter \& Perry. (2005). Buku Ajar Fundamental Keperawatan Konsep Proses Dan Praktik Edisi 4. Jakarta : EGC.

Potter \& Perry. ( 2010). Fundamental Of Nursing : Edisi 7. Jakarta : EGC.

Rohma, N \& Wahid, S. (2009). Proses Keperawattan. Arruz Media. 
Roper, Nancy. (1996). Prinsip-Prinsip

Keperawatan. Yogyakarta : Andi

Yayasan Essentia Medica.

Simamora, R. H. (2009). Dokumentasi

keperawatan. Jamber University Press.

Simamora, R. H. ( 2010). Komunikasi

Dalam Keperawatan. Jamber

University Press.

Simamora, R. H. (2008). Peran

Manajemen Pembinaan Etika Perawat

Pelaksanan Dalam Peningkatan Kualitas

Pelayanan Asuhan Keperawatan. Jurnal IKESMA.

Tarwoto \& Wartonah. (2012).

Kebutuhan Dasar Manusia Dan Proses

Keperawatan. Jakarta : Salemba

Medika. 